BULLETIN Bulletin hispanique

HispaniQuE Université Michel de Montaigne Bordeaux

114-1 | 2012

Varia

\title{
La canción 162 en las Rimas de Burguillos, de Lope de Vega
}

Sus dos versiones y algunas dificultades de interpretación

Ignacio Arellano

\section{OpenEdition}

\section{Journals}

Edición electrónica

URL: http://journals.openedition.org/bulletinhispanique/1815

DOI: 10.4000/bulletinhispanique.1815

ISSN: $1775-3821$

Editor

Presses universitaires de Bordeaux

\section{Edición impresa}

Fecha de publicación: 1 junio 2012

Paginación: 99-115

ISBN: 978-2-86781-812-7

ISSN: 0007-4640

\section{Referencia electrónica}

Ignacio Arellano, "La canción 162 en las Rimas de Burguillos, de Lope de Vega », Bulletin hispanique [En línea], 114-1 | 2012, Publicado el 01 junio 2015, consultado el 01 mayo 2019. URL : http:// journals.openedition.org/bulletinhispanique/1815 ; DOI : 10.4000/bulletinhispanique.1815 


\title{
La canción 162 en las Rimas de Burguillos, de Lope de Vega. Sus dos versiones y algunas dificultades de interpretación
}

\author{
Ignacio Arellano \\ GRISO. Universidad de Navarra
}

Les critiques et les éditeurs ont salué avec les Rimas humanas y divinas del licenciado Tomé de Burguillos, le dernier livre de Lope de Vega, un exemple remarquable de la clarté poétique lopesque. Cependant, bien des poèmes de cette cuvre exigent une lecture conceptiste capable de rendre compte de l'ingénieuse dificulté qui sous-tend les textes. On en trouvera l'illustration dans le commentaire de la canción 162, "Murmuraban al poeta la parte donde amaba, por los versos que hacia».

Las Rimas humanas y divinas del licenciado Tomé de Burguillos, último libro de Lope de Vega, han sido valoradas por criticos y editores como muestra representativa de la claridad poética lopiana. Sin embargo, numerosos poemas de esta obra exigen un tipo de lectura conceptista que sepa interpretar la ingeniosa dificultad que subyace en cada texto. Esta cuestión es ejemplificada a través del comentario de la canción 162, "Murmuraban al poeta la parte donde amaba, por los versos que hacia».

With Rimas humanas y divinas del licenciado Tomé de Burguillos, Lope de Vega's last work, critics and publishers greeted a remarkable example of his poetical clarity. Nevertheless, many poems in this works demand a conceptual reading, able to give an account of the ingenious difficulty underlying the texts. An illustration will be found in the commentary of canción 162: Murmuraban al poeta la parte donde amaba, por los versos que hacía.

Mots-clés : Lope de Vega, conceptisme, annotation de textes.

os estudios y ediciones más recientes que se ocupan de las Rimas humanas
y divinas del licenciado Tomé de Burguillos (1634), libro postrero de Lope,
insisten en el tópico de la claridad de la poesía lopiana, aprecian los rasgos
autobiográficos, regresan a la parodia petrarquista y a la burla anticulterana, 
etc. El epígrafe que la última editora ${ }^{1}$ dedica al «Sentido y forma» (pp. 2731) de esta colección trata de la estructura de cancionero a Juana (que niega), menciona la parodia como clave del conjunto, y alude a la Gatomaquia como ejemplo de parodia épica, y a los poemas de corte religioso como otro componente que enriquece la compleja composición del libro. Pero en ningún momento se considera en esta aproximación al sentido y a la forma del Burguillos el mecanismo del ingenio conceptista, que a mi juicio es la verdadera clave del volumen. Esta marginación de las verdaderas dimensiones del Burguillos (al menos de una dimensión imprescindible) provoca a menudo errados juicios y lecturas poco ajustadas que afectan a muchos poemas ${ }^{2}$, entre ellos a la canción 162. Cuiñas, por ejemplo, en el mismo apartado que acabo de citar, incluye un comentario de cierta extensión sobre esta pieza recordando que Lope había publicado en 1605 una primera versión en las Flores de poetas ilustres de Pedro de Espinosa, circunstancia que curiosamente olvida acto seguido para afirmar que la canción encaja perfectamente en la etapa de senectute (como si hubiera sido escrita originalmente en 1634): «en la vejez quiere cambiar este estilo y hacer olvidar, en cierta manera, sus arrebatos reñidos con su nueva imagen de poeta culto reposado y contenido» (p. 29). Semejante valoración pudiera aceptarse si realmente se produjera un cambio de estilo, cosa que debería resultar bastante clara mediante la comparación de ambas versiones.

Pero el hecho es que la proclamación de «quiero mudar de estilo» ya se lee en la primera versión de 1605: aunque Lope entonces tenía sus años (43) todavía faltaban 29 para la publicación del Burguillos, libro, este sí, que la crítica tiene por característico de la etapa de vejez.

La relación (falsa) establecida entre este poema y los supuestos deseos de Lope de presentarse como poeta culto y contenido en la senectud (cosa que casi todo el jocoso Burguillos niega, por otra parte) ${ }^{3}$ conduce a lecturas 'ennoblecedoras', con 'bellas escenas costumbristas' y otras metamorfosis de fenómenos fisiológicos en flechas de Cupido ${ }^{4}$ que, como se verá, no están en la intención del poeta. Muy ingenua lectura hace Cuiñas cuando afirma que Lope ha reescrito la canción «depurándola de toda procacidad» (p. 29). Ciertamente, si se compara la versión del Burguillos con la de Flores de poetas ilustres, se

1. M. Cuiñas Gómez, introducción a Rimas humanas y divinas del licenciado Tomé de Burguillos, Madrid, Cátedra, 2008. Manejo para mi comentario las ediciones de Antonio Carreńo, Salamanca, Almar, 2002; Juan Manuel Rozas y Jesús Cañas Murillo, Madrid, Castalia, 2005, y Macarena Cuiñas Gómez, Madrid, Cátedra, 2008. Carreño numera dos poemas preliminares, con lo cual esta canción es el poema 164. Para el texto de la canción establezco mi propia edición sobre la príncipe de 1634 .

2. Ver mi libro, en prensa, El ingenio de Lope de Vega. Escolios al Tomé de Burguillos.

3. La mudanza de estilo hay que entenderla en el contexto del poema, no en el 'contexto' de la vida de Lope. Quiere mudar de estilo precisamente para que el vulgacho no presuma de entender las alusiones personales que cree ver siempre en sus versos (ver vv. 1-26), no para ofrecer un estilo ponderado y contenido; todo lo contrario: en la primera versión de 1605 califica a este nuevo estilo de «socarrón». Ver Flores de poetas ilustres, pp. 443-447, sin apenas notas de los editores. Cuiñas reproduce esa primera versión en las pp. 623-626 de su edición.

4. Ver más abajo comentario relativo al v. 240. 
percibe algún refinamiento ${ }^{5}$, pero la verdad es que todo el conjunto obedece a la concepción de lo cómico propia del Siglo de Oro, es decir, la de la turpitudo et deformitas, con explotación de las referencias escatológicas y de las imágenes grotescas.

No me voy a ocupar de toda la extensión del poema: aunque los diversos editores (Carreño, Rozas-Cañas, Cuiñas) discrepan a veces, sumando sus aparatos de notas se puede leer con cierta facilidad una parte de la composición, de manera que me centraré en algunos puntos que me parecen relevantes y que convendría anotar, a los que dedicaré las líneas siguientes. Para facilitar el seguimiento del comentario reproduzco el texto de la canción según la versión del Burguillos:

\section{Murmuraban al poeta la parte donde amaba, por los versos que hacía. Canción}

Ya pues que todo el mundo mis pasiones de mis versos presume,

culpa de mis hipérboles causada, quiero mudar de estilo y de razones y pues la misma pena me consume, tomar la lira menos bien templada. ¡Oh, vos, rubia manada, y todos los demás que, paso a paso, pacéis los alcaceres del Parnaso, prestadme vuestra ayuda sobre prenda, para que el vulgo bárbaro no entienda por mis necios efetos el alma de mis versos y concetos!, que si animando tan humilde estilo, segunda vez pretende comentar mis desdichas, desde agora, de los que habitan el egipcio Nilo o los que en Etiopia el sol enciende $\mathrm{y}$ en los bordados rincones del aurora que Febo infante dora, aprenderé la lengua no entendida, dejando escura fama en larga vida. Mas yo fío, Piérides, que en tanto aflojaréis las cinchas a mi canto y que en este lenguaje el Lete me dará franco pasaje. Riberas del estrecho Manzanares — por donde antiguamente alborotó sus límites postreros

la que tuvo a Jonás en los ijares, escureciendo su cristal corriente la paja y vino del albarda y cueros

5 a fuerza de los fieros dardos y chuzos de la gente armada que por la puente le estorbó la entrada-, un soto, lleno de verdura y caza, donde prueban los toros de la plaza,

10 cubre la orilla amena de chopos, sauces, lirios y verbena. En éste, un martes pardo, aciago y malo 40 para casar doncellas, entre la grama y los menudos juncos

15 vi el sol, a cuya vista me regalo y aquellos ojos como dos estrellas y es poco si dijera dos carbuncos. No desde los aruncos a nuestros montañeses vieron dama

20 tan bella los antojos de la fama. Al fin yo vi su rostro y su aguileña nariz como remate de cermeńa y aquella boca hermosa que dejó de ser guinda por ser rosa.

25 Mas si Cupido, entonces lisonjero, en vez de la sangrienta ballesta de sangrar rocines y hacas, tirome con la mano de un mortero

5. Para las diferencias mayores entre ambas versiones ver el comentario de Rozas-Cańas en su edición, p. 338. Estos editores también insisten excesivamente en la finura irónica y ausencia de escatología del poema de 1634, que, como se verá, no es tan diferente en esto del de 1605. 
que, durmiendo una noche en una venta, hurtó para tirar a las urracas;

tal en indias hamacas

suele desvanecerse, o en la nave, quien ni del mar ni del columpio sabe; quedando yo tan triste y descompuesto como después de las vendimias cesto, dando más estornudos que los tabacos dan por los embudos. No suele el sol más libre y licencioso entrar por un resquicio en un zaquizamí de teja vana que el rayo ilustre de su rostro hermoso, haciendo en mí piramidal solsticio70 con dulce fuerza de opresión tirana, entró por la ventana de aquestos ojos a mi helado pecho, suave ardor de mis sentidos hecho, aunque el fuego, que el humo interrumpía, 75 en densa nube el aire convertía.

Si alguno me miraba, del tufo de mi mal estornudaba. Rapaz Amor, ¿qué es esto? ¿Quién te ha dado fuerza $\tan$ poderosa desde la roja púrpura al plebeyo sayal que sigue el buey con el arado? ¿Qué Pangeo produce aquella rosa, Astolfo del sentido de Apuleyo? ¿Qué César, qué Pompeyo, qué pastor, qué rocín rucio o castaño, no hirió tu flecha ni rindió tu engaño? ¿Qué Adonis, qué Narciso o Filomena en flor o en pluma no lloró tu pena? Todos mueren de amores, César, rocín, pastor, aves y flores. Allí con los ardores del veneno, aunque dulce contrario, a la quietud del corazón rendido, quejeme al soto, al prado, al campo ameno, 95 de aquel mortal arquero Sagitario, desnudo de temor, de error vestido. El río, condolido de lástima, corrió como solía y las aves con dulce melodía animaban los céfiros suaves, que también en las flores eran aves y patos y conejos escuchaban mis penas desde lejos. Álamo no quedó, no quedó fuente, pastor ni lavandera, novillo en soto ni borrico en prado, que no se condoliese tiernamente de ver en su ribera llorar de amor un hombre licenciado, tan docto y tan barbado, como si el alma fuese vieja o nińa,

60 barbada por los lados o lampińa; ni es centro el cuerpo del amor heroico, aunque no soy platónico ni estoico, siguiendo en esta tema aquel aristotélico teorema.

65 Dijo este tal autor, que en griego escribe, por no ser de la Mancha y ser la lengua en que nacido había, que Amor en conyugales lazos vive, y sin ellos también, que tanto ensancha de su juridición la monarquía, que fue sentencia fría, aunque la diga el rey filosofante; no porque la condeno repugnante, pero siendo jüez naturaleza, amable, por ser bien, es la belleza, $y$ sin comunicarse pudiera de Aristóteles quejarse.

Viéndome, en fin, que por las selvas solas sátiro parecía,

80 amante sin dinero, pobre y roto, envidiaba las cándidas tortolas, aunque mayor envidia me afligía de los que merendaban en el soto. Mas cuando más remoto

85 de todo bien sin esperanza estaba, vi que la bella Juana merendaba una empanada con Leonor, su tía, y aunque era el alba de quien sale el día, dejando Amor antojos,

90 a la empanada me llevó los ojos. Si con hambre no hay Venus que aproveche, tanta descortesía disculpe, si de amor fuera culpada, en pan de azúcar un capón de leche; y aunque Juana tan linda parecía, de más sazón estaba la empanada, invención regalada y más que para oír tiples eunucos; si merendaran habas o almendrucos

100 pudiérase quejar de mi deseo, pero entre cuantos platos dulces veo puede comer el Fúcar tiple de teta en círculos de azúcar. No de otra suerte gozque hambriento esgrime

105 blanda flexible cola en torno de la mesa de su dueño $\mathrm{y}$ con lengua anhelante gruñe $\mathrm{y}$ gime, ya con ladrido y ya con cabriola, que yo con muda queja el alma enseńo. 
Ella con el risueño semblante entonces me tiró tirana, aunque fue de marfil la cerbatana, del cadáver pretérito la Troya a manera de torno de tramoya. ¡Oh, terribles excesos, esperando pechugas hallar huesos! Diome en la nuez el golpe, que me hizo sacar toda la lengua como perro con hueso atravesado; mas el favor la pena satisfizo, que no es, amando, mengua salir favorecido y agraviado. Sentime consolado del golpe, que, en señal de mi vitoria, sonó como quien muerde zanahoria, más apacible que al villano oído el dulce son del rábano partido, y como hirió en lo hueco, opuesta resonó la ninfa Eco, mas habiéndole dicho mi accidente, se levantó furiosa, como suele perdiz que del sonante rocín del cazador la estampa siente formando aquella rueda sonorosa del vuelo fugitivo retumbante. El soto, que delante sintió sus caireladas zapatillas, tocaba sus azules campanillas y al pasar cada flor le daba un beso en fe de que era el pie cándido queso, aunque en tales rebatos no sé si eran coturnos o zapatos. No suele algún sardesco, de mañana, de su chozuela pobre salir brioso dando mil carreras, repicando a su son como campana los abollados cántaros de cobre entre las sonadoras aguaderas, ni fueron tan ligeras de Dafne las castizas cosetadas, como de mi enemiga las pisadas y aquel brioso zahareño brío que allá se lleva el pensamiento mío, dejando a mi deseo la pluma que dejó Progne a Tereo. Yo, despechado, por la selva fuime y hallé en la verde grama la hermosa Venus y el rapaz Cupido; ella le riñe y él solloza y gime y viendo que al Amor Amor desama, en la hierba senígena tendido, acomodé el oído,

165 cual se suele poner tierno gazapo y vi que Venus, sacudiendo un trapo, limpiaba con sus manos delicadas de aquel rapaz las cartas atrasadas $y$ triste en ser su madre

170 maldecía el herrero de su padre. «No soy — decía el niño- sino engendro de Marte furibundo, de polvo y sangre y de sudor teñido; bien lo saben las ramas deste almendro

175 y Júpiter y vos y todo el mundo, cuando mejor hubiera producido, de carmesí vestido vuestro rostro las rosas del Pangeo, si la vid y la risa juntas veo;

180 y no es mucho que yo tenga por mayo para mayor salud algún desmayo, que la ninfa más linda y más mirlada suele estar amarilla y colorada».

Reime entonces yo de un licenciado

185 que en todo su juicio me dijo que su dama cristalina nunca tuvo tal género de enfado, sabiendo que el timón del edificio consiste en disparar la culebrina.

190 Aunque Amor desatina, ¡oh, vasallos de Venus!, no os engañe ni el bien que os venga ni el rigor que os dañe, que amor es un compuesto de accidentes a quien los celos dan chazas corrientes

195 y, fénix de sus brasas, purga desdenes con ciruelas pasas. Amor tuvo razón y yo lo fundo en que, por no ser tales, para pañales del señor Cupido

200 se hicieron muchos versos en el mundo que, como de otros lienzos principales, los poetas tal vez los han rompido y es cosa que ha venido a ser fragmento inútil a su dueño;

205 cuando Venus al nińo rinde al sueño, quitando el borrador, pone el traslado, aunque todo después queda borrado.

¡Dichoso aquel conceto que se pudo librar de tanto aprieto!

210 Canción, si acaso vas a pasearte al Prado o a otra parte, pásate por en cas de un alojero y dile cómo muero. 
El poema se organiza en varias secuencias:

1) Introducción, con invocación a las Musas (vv. 1-26)

2) Localización espacial: riberas del Manzanares, con referencia jocosa al cuentecillo de la ballena (vv. 26-39)

3) Episodio central: encuentro amoroso paródico con Juana, la merienda campestre, enfado y marcha de la lavandera (vv. 40-208)

4) Paseo despechado del poeta y encuentro con Venus y Cupido (vv. 209260)

5) Envío o cierre (vv. 261-264)

En la primera secuencia el poeta proclama su intención de eludir a los lectores del vulgacho que murmuran de los amoríos del poeta que hallan en sus versos. Es conocida la presencia de elementos autobiográficos en los versos de Lope, pero en esta ocasión el locutor pretende esconder esos detalles escribiendo en un lenguaje inaccesible para el vulgo, objetivo que espera lograr con ayuda de las musas, o aprendiendo lenguas exóticas que pocos entiendan.

La invocación del v. 7 « $\mathrm{Oh}$ vos, rubia manada!», solo la comenta Cuiñas, quien la interpreta como una «sátira burlesca hacia otros poetas, probablemente los gongorinos, a quienes ridiculiza presentándolos como rebaño que pace en el monte Parnaso", pero se trata en realidad de alusión a las musas, que como buenas damas hermosas auriseculares serían rubias (ver el v. 23 «yo fío, Piérides...», que confirma mi interpretación). Todos los demás que pacen los alcaceres (cebada verde) del Parnaso (v. 9) a quienes pide ayuda sí serían otros poetas, pero no los gongorinos, sino los considerados dignos del Parnaso, aunque expresado todo en tono burlesco, identificando a esos poetas con un rebaño de ganados. A todos pide ayuda (tópico de la invocación a las musas), añadiendo la coletilla burlesca de pedirla «sobre prenda» (v. 10), es decir, dando garantía, como si fuera un trato comercial. En la versión de 1605 se aprovechaba la oportunidad para hacer un chiste escatológico: "vuestra ayuda o melecina», jugando dilógicamente con el sentido de ayuda "lavativa, enema".

Si el vulgo pretende seguir murmurando sus desdichas amorosas, el poeta aprenderá la lengua no entendida que hablan los egipcios, o los etíopes (vv. 16-22).

A partir del v. 27 narra los sucesos que constituyen la trama central del poema, en ese lenguaje socarrón y burlesco que intenta ser difícil para el vulgo murmurador.

La secuencia segunda sitúa el escenario de la acción en las riberas del Manzanares, y alude a un cuentecillo bien conocido seguramente por los receptores del Siglo de Oro, desarrollado en los vv. 27 y ss. Convendrá añadir algunas observaciones, porque el texto produce alguna confusión en las notas que se le han dedicado.

Carreño explica:

La referencia a Jonás en los ijares la documenta el libro bíblico del mismo nombre. [...] Alude Lope al origen mítico del pueblo que habitaba las orillas 
del río Manzanares («antiguamente») asociado con una ballena; de ahí que a los madrileńos se les reconociera con el apodo de 'ballenatos'.

Rozas-Cañas citan una nota sucinta de Blecua: "Alusión a la conocida anécdota de la ballena y a llamarse ballenatos los madrileños».

Cuiñas Gómez, por su parte escribe:

Esta estancia se refiere a un suceso ocurrido en el Manzanares por el cual los habitantes de sus riberas fueron llamados ballenatos: asaetearon unos odres de vino tinto creyendo que era una ballena. De esta anécdota se hace eco Lope en El galán escarmentado [...] y La noche de San Juan, así como otros poetas de su tiempo...

Cuiñas remite a Fradejas ${ }^{6}$, quien aporta con mayor claridad los testimonios necesarios para comprender la burla de Burguillos, poco clara en las anotaciones de los sucesivos editores. Hay dos versiones de esta ballena: una según la cual los rústicos asaetean unos odres que iban por el río; otra en la que confunden una albarda con una ballena. El texto de Burguillos funde ambas (menciona la paja y el vino de la albarda y de los cueros respectivamente). En El galán escarmentado Lope se refiere a los cueros de vino:
-En efecto es fingimiento
lo del río y el jumento
con los dos cueros de vino.
-Que le trujo la creciente
entre el agua y el arena,
y llamándola ballena
salio a matarla la gente
es antigua tradición.

Pinheiro da Veiga en su Fastiginia recoge la versión de la albarda:

a las de Madrid [llaman] ballenatas porque cuando hablan de su Manzanares les levantan que llevando una albarda la crecida acudieron todas diciendo que traía un tiburón o ballena...

La descripción más amplia y elaborada del cuentecillo es la de Castillo Solórzano en Jornadas alegres, de la que saco algún extracto a través de Fradejas:

llegó, pues, la terrible ballena, cercada de espumas y ramas que a ella habían agregado las olas del furioso Mancia Henares; emparejó con el andamio y aquella villana cuadrilla prevenida cum fustibus et armis, descargó en ella su cólera, sin perdonarle ninguno su riguroso golpe de espada, chuzo, dardo o piedra [...] Finalmente, herido de todos, fue fuerza descubrir las entrañas por las roturas del pellejo...

6. J. Fradejas, Geografia literaria de la provincia de Madrid, Madrid, CSIC, 1992, pp. 72-78. Cuiñas solo apunta uno de los elementos del cuentecillo, el de los odres, ignorando el asunto de la albarda, que es el que explica la mención lopiana de la paja en el v. 32. 
Habían matado el albardón de un asno.

En ese ámbito topa Burguillos con Juana, a cuyo retrato y efectos de su belleza en el amante licenciado dedica los vv. 43 y ss. Menudean las imágenes y agudezas cómicas. Creo que la mayoría se comprenden bien. Apuntaré solo algunos rasgos puntuales. El v. 55 metaforiza la flecha amorosa de Cupido en una ballesta de sangrar rocines y hacas, metáfora degradadora que sugiere la necedad y animalización de los enamorados, intensificada en los versos siguientes: en efecto, Cupido no ha herido a Burguillos con la flecha-ballesta sino con un majadero o mano de mortero, símbolo del necio ${ }^{7}$. La metáfora de la ballesta, dicho sea de paso, no remite (o no remite solo) al arco de Cupido (como asegura Cuiñas entendiendo cuasi sinónimo arco y ballesta), sino a la ballestilla "cierto instrumento de hierro a modo de ballesta pequeña de que suelen usar los albéitares para sangrar las bestias caballares, aunque ya más comúnmente usan de otro llamado fleme» $(A u t)$. La vista de Juana produce en Burguillos desvanecimientos y estornudos, como si se hubiera columpiado en una hamaca o mareado en un barco, o como si hubiera tomado polvo de tabaco, que provocaba estornudos ${ }^{8}$. Los vv. 65-76 siguen describiendo el mecanismo amoroso en términos paródicos: según la teoría amorosa vigente, los «espíritus visivos» o pequeñas partículas emitidas por los ojos de la amada o el amante, penetraban por los del otro enamorado causando el efecto de la pasión. El amor entraba por la vista según un tópico que no hace falta documentar. Por las ventanas de los ojos de Burguillos entra el rayo solar del resplandeciente rostro de Juana y enciende en su pecho un incendio amoroso (vv. 70-74) que en este caso burlesco produce una humareda que hace estornudar a los circunstantes.

Hay ciertas duda sobre la expresión «piramidal solsticio» (v. 70). Para RozasCañas puede ser alusión a la pirámide óptica («Es una pirámide comprendida de los rayos ópticos principales, que tiene por base al objeto [Lope, en sí] y por cúspide al centro de cualquiera de los ojos [de Juana] [...] Lope estaría, bajo el sol de verano del rostro de ella, como el objeto en el aparato óptico»); para Cuiñas "por la forma del tejado, que puede ser metáfora del poeta, en el que entra el sol, que es la dama, y "solsticio" por la luz que irradia". La explicación de Rozas-Cañas me parece demasiado complicada y sin fundamento textual; la de Cuińas ignora la distribución metafórica del pasaje, que consiste en una comparación que parodia a las épicas: igual que el sol entra por los resquicios de un tejado entra por los ojos de Burguillos la luz del rostro de Juana. El tejado no es metáfora del poeta. El texto dice que el rayo de Juana 'hace en el poeta piramidal solsticio', lo convierte en un solsticio piramidal. Solsticio porque es el momento de mayor dominio del sol (se supone que es solsticio veraniego, no

7. «Llamamos majadero al necio, por ser boto de ingenio, como lo es la mano del mortero, a que se hace la alusión» (Cov.).

8. No se puede descartar para estornudos un sentido escatológico 'ventosidades', bastante corriente en la lengua burlesca del Siglo de Oro. Comp.: «Dábale priesa el retorno / de la mal sorbida zupia; / las tripas tocan al arma, / el un ojo le estornuda» (F. de Quevedo, Un Heráclito cristiano, ed. I. Arellano y L. Schwartz, Barcelona, Crítica, 1998, Romance dedicado al suceso ridículo del trueco de dos medicinas, un afrodisíaco y una purga, núm. 283, vv. 133-136). 
invernal) y piramidal por alusión a la forma de la llama, pues que lo convierte en una llama ardiente. Piramidal es epíteto tópico de la llama, baste comparar este texto de Quevedo?:
¿No ves, piramidal y sin sosiego
en esta vela arder inquieta llama,
y cuán pequeño soplo la derrama
en cadáver de luz, en humo ciego?

Aut. define la llama como «la parte más sutil del fuego, que se eleva y levanta a lo alto en figura piramidal».

Los vv. 83-84 ofrecen una oportunidad excelente para ejemplificar el tipo de lectura que no funciona en los poemas del Burguillos, -en general en la poesía conceptista del Siglo de Oro-, y a la vez evidenciar los requisitos necesarios para su comprensión. El pasaje en el que se insertan pondera la todopoderosa fuerza del amor, que domina «desde la roja púrpura al plebeyo / sayal», enajenando a pastores y emperadores, a las aves y a los brutos, a Césares y Pompeyos, Adonis y Narcisos, y a todo el mundo. En cierto momento de estas ponderaciones del poder de Amor y sus efectos, el locutor enamorado, se pregunta:

¿qué Pangeo produce aquella rosa,

Astolfo del sentido de Apuleyo?

Las notas de los editores tratan independientemente los motivos sin llegar a plantearse cuál es la relación que los une y cuál es el sentido global de los dos versos que comento.

En la edición de Carreño:

Pangeo violó involuntariamente a su propia hija, por lo que se suicida atravesándose con su propia espada en el monte que lleva su nombre.

Astolfo: héroe de la literatura caballeresca francesa y prototipo en la literatura épica italiana del personaje cómico y ocurrente; así por ejemplo en el Morgante de Pulci. Se establece una analogía entre este héroe y el Lucio del Asno de oro de Apuleyo, convertido en jumento, aunque dejaría de serlo si comiera determinadas flores.

En la de Rozas-Cańas:

Lucio Apuleyo de Madaura escribió El asno de oro, novela en la que el protagonista, Lucio, es convertido en burro y solo puede recuperar su forma humana cuando al final un sacerdote de la diosa Isis le da a comer una corona de rosas. El Pangeo es un monte de Macedonia cuya denominación tiene un origen mítico, pues se cuenta que un héroe tracio llamado Pangeo, hijo de Critobule y Ares, se dio muerte en él -por lo que en recuerdo le prestó su

9. F. de Quevedo, Poesía original, ed. J. M. Blecua, Barcelona, Planeta, 1981, núm. 345. vv. $1-4$. 
nombre- cuando descubrió que sin saberlo había violado a su propia hija. Como explica Blecua «Astolfo es un viejo héroe de la literatura caballeresca francesa, que pasa a los poemas italianos del tipo del Orlando, como personaje cómico y simpático, y vencedor a ratos sin saberlo, como le ocurre en el Morgante de Pulci».

Y en la última de Cuiñas:

Pangeo: héroe tracio, hijo de Ares y de Critobule. Habiendo violado, sin querer, a su propia hija, se traspasó con su espada en el monte que en recuerdo suyo tomó el nombre de Pangeo. En este verso se pregunta por qué el monte, Pangeo, ha producido esta rosa, la dama, el amor. Estas rosas también están citadas en el verso 229.

Astolfo: personaje de la literatura caballeresca francesa e italiana en las que aparece como valiente caballero contemporáneo de Roldán. Personaje cómico y simpático. Aparece ya en Boyardo y de este Astolfo deriva el de Ariosto (Orlando furioso).

La referencia en estos versos a Apuleyo, escritor clásico, es a la rosa, puesto que Lucio, héroe del Asno de oro, transformado en este animal, debía comer rosas para recuperar su forma humana [...] En cierta forma este verso identifica al héroe Astolfo con Lucio.

Ninguna de las informaciones que aportan las notas sirve para entender el texto de Lope. La historia del personaje Pangeo no ilumina al poema de Burguillos, porque no procede en el contexto. Que Astolfo fuera simpático o no, es igualmente irrelevante.

En la explicación de Cuiñas se afirma que el monte Pangeo produce «la dama, el amor», como si rosa fuera metáfora para la dama o para el amor (¿para la dama o para el amor?, porque son dos cosas distintas), y se identifica Astolfo con Lucio. Si «tradujéramos» esa identificación aplicándola a los versos de la canción lopiana quedaría que la "dama» era por tanto «Lucio del sentido de Apuleyo», expresión ininteligible.

Antes de intentar una interpretación debe analizarse la estructura aguda de los versos: el poeta establece una relación de Pangeo con la rosa, y por tanto habrá que explicarla, sin desviar la atención hacia la historia trágica en sí misma del personaje. Establece también una relación de Astolfo con la rosa (el v. 84 es yuxtaposición metáforica al v. 83: la rosa se identifica con Astolfo); y otra relación de Astolfo con el «sentido de Apuleyo», por lo que habrá que descubrir por qué causa se menciona a Astolfo en este contexto en el que la comicidad o simpatía del personaje no hace al caso.

La primera correspondencia de Pangeo con la rosa es la más sencilla: en el monte Pangeo se colocaban los legendarios jardines de rosas del rey Midas, y las rosas del Pangeo se mencionan constantemente en la literatura aurisecular (v. 299 «las rosas del Pangeo» en este poema que anoto ahora). Lope en El laurel de Apolo ${ }^{10}$ :

10. L. de Vega, Laurel de Apolo, ed. A. Carreño, Madrid, Cátedra, 2007, p. 150. Carreño, que apunta otros útiles lugares de Lope con esta mención, identifica el trofeo que produce el Pangeo 
más laureles se finge y más trofeo

que produce Pangeo,

mejillas del Aurora

si así llama las rosas que colora (I, vv. 243-246).

¡Oh dulces hipocrénides hermosas,

los espinos pangeos

aprisa desnudad y de las rosas

tejed ricas guirnaldas y trofeos

a la inmortal doña María de Zayas!

(VIII, vv. 579-583)

Dice de la rosa en el poema "La rosa blanca»:

Nació encarnada del rubí sangriento que de Venus vertió la planta herida; no fue primero blanca, y del violento golpe en las zarzas con el pie teńida ofrece la verdad el argumento que hoy se consagra a tu beldad florida en cuya mano cándida la veo más bella que en las cumbres del Pangeo ${ }^{11}$.

Y en la misma Dorotea:

Mejor durmiera yo en esta que en los jardines de Chipre o entre las rosas del monte Pangeo, hibleas o elisias flores ${ }^{12}$.

Etc. Es decir, que lo que importa en el texto de Burguillos es la relación del Pangeo con las rosas. Para defenderse del amor hace falta una rosa especial: ¿qué Pangeo -lugar de abundantes rosas- especial producirá esa rosa especial? es lo que se pregunta el v. 83 .

Esa condición de antídoto contra la fuerza poderosa del amor permite ahora llamar a esa hipotética rosa "Astolfo»: el nombre del personaje caballeresco es una metáfora cuyo referente es "rosa». Podríamos llamar "Astolfo» a esa rosa pangea. Ponderación misteriosa -diría Gracián-, hay en esa semejanza propuesta. ¿Por qué motivo se puede aplicar a la rosa 'antídoto amoroso' el nombre de Astolfo? Porque Astolfo, según cuenta Ariosto en su Orlando furioso (ver cantos 34 y 39) viaja a la luna, donde encuentra el seso que Orlando ha perdido por amor de Angélica; recuperada la ampolla donde se guarda la razón del paladín, Astolfo regresa y hace que Orlando aspire su razón perdida, recuperando así su capacidad racional ${ }^{13}$ :

con sus minas de oro, pero Lope se refiere a las rosas.

11. L. de Vega, La Circe en Obras poéticas, ed. J. M. Blecua, Barcelona, Planeta, 1983, p. 1061 .

12. L. de Vega, La Dorotea, ed. E. Morby, Madrid, Castalia, 1980, p. 284. Anota Morby: «Son proverbiales las rosas del monte siciliano Hibla y del tracio Pangeo».

13. Nada importa su simpatía o comicidad, ni ninguna otra noticia sobre el personaje, salvo 


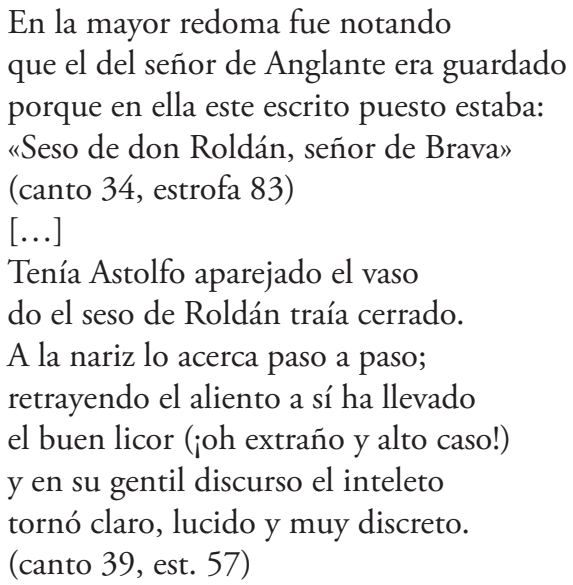

Si en el Asno de oro de Apuleyo, Lucio recupera su ser racional al comer las rosas, dejando la forma de asno, a Orlando le pasa lo mismo cuando se cura de su demencia amorosa al insuflarle Astolfo el seso que había perdido. La rosa de Lucio podría también llamarse "Astolfo", en cuantos ambos restauran la razón, pero en ese caso sería "Astolfo del sentido de Apuleyo", donde «Apuleyo» funciona como metonimia alusiva a Lucio (el autor de la obra por el protagonista) $)^{14}$.

En resumidas cuentas, lo que el enamorado Burguillos necesitaría para precaverse de la locura amorosa es una rosa pangea que tuviera las propiedades de la rosa del Asno de oro, o lo que es lo mismo, que desempeñara la función de Astolfo.

Los vv. 92-136 desarrollan otro tópico, el de las quejas amorosas del amante, del cual se compadece la naturaleza. No hace falta señalar el tono jocoso: el río, condolido, "corrió como solía» (v. 99), etc. Integra una reflexión filosófica sobre el amor, con alusión a doctrinas aristotélicas y platónicas. Defiende Burguillos la existencia del amor dentro y fuera del matrimonio, porque es natural que la belleza atraiga y si el bien y la belleza se identifican, la belleza ha de ser comunicable, según enseña Platón. Toda esta digresión, aplicada a la atracción que le provoca Juana es, no hay que decirlo, recurso paródico, que se refuerza con los motivos de la merienda: más aún que las penas amorosas le aflige el espectáculo de los que engullen en el soto, mientras él pasa hambre. Entre los que se gratifican con una suculenta merienda descubre a Juana. Ahora, más que la belleza de la amada, lo atrae la empanada que comen, argumentando que «con hambre no hay Venus que aproveche» (v. 144), alusión a la frase clásica procedente del Eunuco de Terencio «Sine Cerere et Libero friget Venus», 'Sin Ceres y Baco se enfría Venus', que se hizo proverbial para indicar que los placeres del amor suelen ir unidos a los de la mesa.

su misión de restituir a Orlando el seso perdido. Cito el texto del Orlando por la traducción de Jerónimo de Urrea (1549).

14. Pues en realidad la rosa sería 'Astolfo o agente restaurador del sentido de Lucio'. 
Este verso introduce un pasaje humorístico en el que Burguillos -hambriento y pobre, como buen poeta- se disculpa por prestar más atención a los manjares que merienda Juanilla que a la propia amada. En su descripción de la comida se refiere a un capón de leche en pan de azúcar (vv. 144-156), pasaje bastante aclarado por el contexto, pero al que anota Cuiñas «tiple de teta en círculos de azúcar. Quizá sea vino joven con azúcar. De este modo tendríamos una dilogía: el término "tiple" tiene dos significados diferentes en el verso 151 y en este 156. Aquí posee el que se le otorga en la germanía: "el vino"». Rozas-Cañas tampoco aciertan al proponer para "teta. Puede aludir a un dulce llamado teta de vaca». Carreño no se ocupa directamente de este pasaje, quizá por considerarlo claro.

Lo que dice Burguillos es que el capón de leche en azúcar es manjar digno de los potentados banqueros de la familia de los Fúcar ${ }^{15}$. Le llama tiple al capón (no al vino, ni joven ni añejo) porque los castrados tienen voz aguda; le llama de teta porque es un capón de leche (alimentado con harina amasada con leche; era manjar exquisito); está en círculos de azúcar porque se sirve en un pilón de azúcar o pan de azúcar. Este tiple es más que para oír; es para comérselo, y siendo digno de los Fúcares, disculpará Juana que se olvide un poco de ella, lo que sería imperdonable si la olvidara por comer habas o almendrucos, pero razonable ante semejante capón de leche.

Cuando espera Burguillos comer algo de ese capón, Juana se burla de él y le tira solo los huesos:

\author{
Ella con el risueño \\ semblante entonces, me tiró tirana, \\ aunque fue de marfil la cerbatana, \\ del cadáver pretérito la Troya... (vv. 163-166)
}

Carreño anota el significado literal de cerbatana («tubo alargado a modo de cańón...», etc.); nota correcta, pero incompleta, porque se trata de una metáfora, y no hay ninguna cerbatana de marfil en ese verso. Carreño seguramente considera innecesario explicar la metáfora, pero las notas de otros editores revelan que no es tan fácil de comprender. Rozas-Cañas, por ejemplo, entienden bien la metáfora de la cerbatana, pero no lo que sucede en el poema: «Ella le tiró con la cerbatana de marfil, con su blanca mano, el pretérito cadáver (el hueso del que fue animal) con lo que ahí fue Troya, con lo que se armó la guerra, con lo que se inició un "acontecimiento desgraciado o ruidoso" sin pensar en las consecuencias». Y Cuińas no entiende la metáfora: «Troya: esta ciudad está citada en esta ocasión como lugar devastado, como los huesos (marfil) que tira Juana al poeta, restos de la "grandeza" pasada, la comida".

Lo que dice el texto es que Juana, con su mano, blanca como el marfil (vista en metáfora de cerbatana porque con ella arroja un proyectil), tira los huesos del capón a Burguillos. El marfil no es metáfora de los huesos, sino de la mano

15. Estos banqueros, y otros significados literales del capón de leche, del pan de azúcar, etc. los aclaran bien los anotadores. Solo falta, otra vez, saltar de las notas literales a la explicación contextual de las correspondencias ingeniosas. 
de Juana. No se arma ninguna batalla troyana: Troya (ahí acierta Cuiñas) es imagen de la devastación: la Troya del cadáver pretérito son los restos o ruinas del capón, comido por Juana, que solo ha dejado los huesos. Nótese que «del cadáver pretérito la Troya» es objeto directo de «me tiró», y lo que le tira son los huesos del capón, lo que niega la interpretación de Rozas-Cañas, que no tienen en cuenta la sintaxis para su lectura, arrastrada seguramente por el recuerdo de la frase hecha "Aquí fue Troya. Dícese cuando hay escarapela, o en lugar donde la hubo» ${ }^{16}$, que sin embargo no es pertinente en el contexto.

El esqueleto del capón le golpea en la garganta a Burguillos (en la nuez) «y como hirió en lo hueco / opuesta resonó la ninfa Eco» (vv. 181-182), versos que al parecer no han entendido los anotadores. Carreño cita el pasaje paralelo del poema de 1605, pero sin mencionar precisamente los versos que citan a Eco (que apoyan la interpretación que daré acto seguido), y anota la historia de Eco y Narciso, considerando a la ninfa «un bello símbolo de la enamorada no correspondida». Rozas-Cañas y Cuiñas también se limitan a explicar quién era la ninfa Eco. Pero en el texto del Burguillos constituye una alusión que habrá que explicar. En efecto, designa metonímicamente un ruido que 'hace eco' en la parte opuesta a la garganta, y que es producto del sobresalto que el golpe en la nuez causa a Burguillos. En la versión de 1605 el sentido de este sonido queda más claro: "y como dio en lo hueco / abajo respondió la ninfa Eco». En resumen, suelta una ventosidad. La extrema depuración del poema es menos refinada de lo que algún editor sostenía. No es extraño que Juana se vaya furiosa, caminando con energía que permite compararla con el burro del aguador que sale brioso por las mañanas, entre otras comparaciones paródicas de la técnica de la epopeya.

A continuación el amante, despechado, se va por la selva y encuentra a Venus y Cupido en una escena grotesca y doméstica: Venus está limpiando el trasero a Cupido y le riñe por haberse ensuciado.

A juzgar por la situación cómica escatológica, la hierba senígena del prado (v. 214) no parece ser la hierba vieja propia de barbechos y campos sin labrar (Blecua, Carreño, Rozas-Cañas, Cuiñas) sino alusión más precisa al sen o sena «hierba medicinal purgativa» (Cov.), cuyas propiedades las trata DioscóridesLaguna, III, cap. 79:

la sena contiene dentro de sus hollejos cierta simiente menuda [...] sácase la virtud de la sena por vía de infusión [...] se suele añadir otras cosas [...] purga la sena con grandísima facilidad la melancolía y la cólera adusta $[\ldots]$ extirpa la lepra y la sarna...

Quevedo, en contextos igualmente escatológicos, censura a un médico que a fuerza de purgas mata a sus pacientes «a puro sen y pugín»; o se burla del novio que se equivoca de medicina y toma un purgante en vez de un afrodisíaco, de modo que la novia ha de huir "del sen que al novio embadurna» (Poesía original, núms. 749 , v. 48; 759, v. 172).

16. Ver G. Correas, Vocabulario de refranes y frases proverbiales, ed. digital R. Zafra, PamplonaKassel, Universidad de Navarra-Edition Reichenberger, 2000, refrán 2853. 
El v. 224 que Cupido aplica a su supuesto padre Marte «de polvo y sangre y de sudor teñido», aunque no lo apuntan los editores, es cita de Garcilaso, «Oda a la flor de Gnido» (v. 15).

Cupido se disculpa por su «accidente» y Burguillos, al oírlo, se ríe de un licenciado que ponderaba la extraordinaria condición de su dama; dice el dios del amor:

no es mucho que yo tenga por mayo

para mayor salud algún desmayo,

que la ninfa más linda y más mirlada

suele estar amarilla y colorada.

Y comenta el locutor, que escucha las palabras de Cupido:

Reime entonces yo de un licenciado

que en todo su juicio

me dijo que su dama cristalina

nunca tuvo tal género de enfado,

sabiendo que el timón del edificio

consiste en disparar la culebrina... (vv. 231-240).

Ningún editor se ocupa del pasaje, que sin duda es alusión grotesca a los excrementos y menstruación: la ninfa más hermosa, asegura Cupido, padece estas servidumbres; él también está sujeto a estos percances defecatorios. Para el significado de amarillo en estos conceptos ver un soneto de Quevedo ${ }^{17}$ en el que el ojo del culo "guińará, con lo amarillo y flojo / todas las veces que a pujar se siente» o el núm. 59 del Burguillos, en el que por efectos del miedo que les causa un toro las calzas de la guarda tudesca que eran amarillas por fuera se ponen también amarillas por dentro. Como se puede percibir, Lope no ha eliminado en absoluto los rasgos escatológicos del poema original.

La explicación literal de culebrina (v. 240; Rozas-Cañas «La pieza de artillería del primer género...», etc.) es insuficiente, y considerar esta culebrina «metáfora de las flechas de Cupido» (Cuiñas) evidencia que esta última editora no comprende el texto malicioso. Tampoco lo han comprendido Rozas-Cañas, quienes aseguran que en esta estrofa «Desaparece lo escatológico».

En sustancia viene a decir: «Al ver a Cupido sucio de excrementos, y oír su argumentación de que cualquier dama por hermosa que sea defeca y menstrua, me reí yo de un licenciado que aseguraba que su dama cristalina (limpia, pura como el cristal) nunca padeció tal cosa, sabiendo que el edificio corporal se gobierna disparando la culebrina (evocación fónica de "culo": es decir, la salud se gobierna defecando lo necesario)». Es la única explicación que cumple con todas las coherencias exigibles a la lectura.

Es tópica la relación de la salud con la buena evacuación: «Cagar bien y mear claro, cagajón para el cirujano" (Correas, refrán 4324); "Comer bien, y cagar fuerte, y no haber miedo a la muerte» (Correas, refrán 4979)...

17. F. de Quevedo, Poesía original, núm. 608, vv. 7-8. 
La versión publicada en las Flores de poetas es más clara y sirve de ayuda para comprender la del Burguillos:

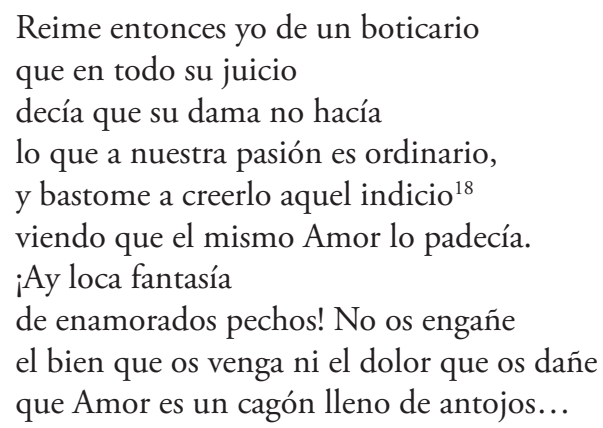

Los versos finales constituyen una burla literaria de los malos poetas, cuyos versos (a menudo plagiados y copiados de "otros lienzos principales») solo sirven para menesteres higiénicos. Cuando Cupido se duerme Venus le quita el pańal sucio (borrador) y pone uno limpio (traslado) que después se ensucia de nuevo («todo después queda borrado»), expresado ingeniosamente con una breve alegoría en términos de documentos copiados (borradores, traslados...).

El envío cierra paródicamente la canción, al dirigir el poema a la tienda de un vendedor de aloja, refresco típico y de gran importancia en la vida cotidiana del Siglo de Oro.

El tono de la canción, por tanto, es plenamente burlesco, y solo la comprensión de los juegos y alusiones desarrollados en el nivel conceptista e ingenioso de la composición permite captar sus verdaderas dimensiones, más allá de la apariencia que se ofrece a la lectura superficial de los motivos más o menos petrarquistas. La depuración que se advierte respecto de la versión inicial no opera sobre el refinamiento temático, sino sobre la elaboración ingeniosa. Si la versión del Burguillos parece más 'limpia' es fundamentalmente porque se encubre con la dificultad ingeniosa la abundancia de referencias escatológicas y burlescas. Pero desde luego no han desaparecido; solo se han hecho más recónditas para provocar la participación del lector cuyo ingenio sea capaz de responder al del socarrón licenciado Tomé de Burguillos.

18. Entiéndase «bastome a creer que sí hacía lo que es ordinario a nuestra pasión (sí defecaba) viendo que el mismo dios Amor estaba sujeto a tal servidumbre». 


\section{BibLIOGRAFÍA}

Arellano I., El ingenio de Lope de Vega. Escolios a las Rimas humanas y divinas del licenciado Tomé de Burguillos. En prensa.

Aut., Diccionario de Autoridades, Real Academia Española, ed. facsímil. Madrid, Gredos, 1990, 3 vols.

Correas G., Vocabulario de refranes y frases proverbiales, ed. digital R. Zafra, Pamplona / Kassel, Universidad de Navarra / Edition Reichenberger, 2000.

Cov., Covarrubias, S. de, Tesoro de la lengua castellana o española, ed. integral e ilustrada de I. Arellano y R. Zafra, Madrid, Iberoamericana, 2006.

Espinosa P., Flores de poetas ilustres, ed. I. Pepe Sarno y J. M. Reyes Cano, Madrid, Cátedra, 2006.

Fradejas J., Geografía literaria de la provincia de Madrid, Madrid, CSIC, 1992 (edición corregida y aumentada).

Quevedo F. de, Poesía original, ed. J. M. Blecua, Barcelona, Planeta, 1981.

- Un Heráclito cristiano. Canta sola a Lisi y otros poemas, ed. I. Arellano y L. Schwartz, Barcelona, Crítica, 1998.

Vega Lope de, La Dorotea, ed. E. Morby, Madrid, Castalia, 1980.

- Laurel de Apolo, ed. A. Carreño, Madrid, Cátedra, 2007.

- Obras poéticas, ed. J. M. Blecua, Barcelona, Planeta, 1983.

- Rimas humanas y divinas del licenciado Tomé de Burguillos, ed. M. Cuiñas Gómez, Madrid, Cátedra, 2008.

- Rimas humanas y divinas del licenciado Tomé de Burguillos, ed. A. Carreño, Salamanca, Almar, 2002.

- Rimas humanas y divinas del licenciado Tomé de Burguillos, ed. J. M. Rozas y J. Cañas Murillo, Madrid, Castalia, 2005.

- Rimas humanas y divinas del licenciado Tomé de Burguillos, Madrid, Imprenta del Reino, 1634. 